Ensino, Saúde e Ambiente - V9 (3), pp. 269-282, Dez. 2016

\title{
QUANDO A UNIVERSIDADE VERTE PARA A CIDADE: EMANCIPANDO E FORMANDO SUJEITOS ATRAVÉS DE AÇÕES NO TERRITÓRIO
}

\section{WHEN THE UNIVERSITY POURS INTO THE CITY: EMANCIPATING AND EDUCATING SUBJECTS THROUGH ACTIONS IN THE TERRITORY}

\author{
Paula Land Curi ${ }^{1}$, Julia Gonçalves Barreto Baptista ${ }^{2}$ \\ ${ }^{1}$ Universidade Federal Fluminense/Instituto de Psicologia, e-mail: paulalandcuri@id.uff.br \\ ${ }^{2}$ Universidade Federal Fluminense/Instituto de Psicologia, e-mail: juliagbbaptista@ gmail.com
}

\begin{abstract}
RESUMO
Este trabalho pretende discutir a formação em psicologia, a partir da aposta que isto pode se dar de forma múltipla, atravessando a cidade, incidindo no território e na população, através de ações, no âmbito da Extensão universitária. Não só a formação em psicologia passou por significativas mudanças nas últimas décadas, mas também a própria universidade. Ambas, consequentemente, enfatizaram seus compromissos com a democracia e a cidadania, dando prevalência a uma forma de produção de conhecimento totalmente articulada com a sociedade na qual se está inserido. Deste modo, faz-se fundamental discutir o papel da Extensão universitária, braço formativo que, por princípio, verte para e na cidade, não só como potência emancipadora de sujeitos, mas também fundamental para a formação de um profissional psicólogo ético-politicamente comprometido com as questões que atravessam a polis. Pretende, também, evidenciar como se faz necessária à formação do profissional psi o encontro com temáticas transversais, cotidiana e continuamente presentes na sociedade.
\end{abstract}

Palavras-chave: Formação, Extensão Universitária, Sociedade, Cidade, Emancipação

\begin{abstract}
This paper intends to discuss formation in psychology, from a bet that this can occur in multiple forms across the city, focusing on territory and population, through actions within the university extension. Not only training in psychology has undergone significant changes in recent decades, but also the university itself. Both, therefore, emphasized their commitment to democracy and citizenship, giving priority to a fully articulated form of knowledge production with the society in which it is inserted. Thus, it is important to discuss the role of university extension, formative arm, in principle, that sheds for and in the city, not only as emancipatory power of subjects, but also essential for the formation of a professional ethical and politically committed psychologist issues that cross the polis. Also aims to show how it is necessary to the formations of professionals the meeting with transversal themes, daily and continuously present in the society.
\end{abstract}

Key words: Formation, University Extension, Society, City, Emancipation 
Ensino, Saúde e Ambiente - V9 (3), pp. 269-282, Dez. 2016

\section{INTRODUÇÃOO}

Através deste trabalho, procuraremos nos dedicar a uma discussão sobre a formação em Psicologia, apostando que esta pode se dar de forma múltipla, atravessando a cidade, incidindo no território e na população, através de ações, no âmbito da Extensão universitária.

A violência contra a mulher, temática eixo de nossas ações extensionistas, é tomada por nós como um problema de saúde pública, que produz agravos em saúde e que se articula às questões de direitos humanos individuais e coletivos. É uma problemática que perpassa várias esferas de nosso cotidiano e que já se encontra, há vários anos, sendo discutida sob o atento olhar das secretarias que promovem politicas públicas para as mulheres. Todavia, ela não ganha devida evidência na formação universitária em Psicologia, exceto quando se apresenta como tema caro a algum determinado docente, cuja trajetória individual, de ativismo, impele-o a construir ações extensionistas voltadas a ela.

Não nos cabe, aqui, discutir as Diretrizes Curriculares Nacionais para os Cursos de Psicologia, nem mesmo questionar o porquê de não lutarmos por incluir a obrigatoriedade desta temática, tão atual como transversal. Nosso intuito é apenas o de salientar como podemos e porque lançar mão da Extensão universitária para sanar algumas lacunas, sempre presentes, em qualquer formação que preze pela emancipação dos sujeitos envolvidos, quer cidadãos, quer discentes.

Se tomarmos a formação como um caminho que vai ganhando complexidade e que não se esgota jamais, a formação é um eterno caminhar 'entre'. Entre sujeitos e saberes diversos, entre espaços e tempo diversos, entre práticas e problemáticas cotidianas. Ela não é apenas circunstancial e não pode se apresentar, nem como uma forma-sem-ação, nem como uma formatação.

Assim, ao explicitarmos, com este trabalho, o eixo privilegiado da Extensão universitária, apostamos numa determinada formação que faz um movimento para fora, um formar-com-ação, que se dá a partir de um transbordamento, propiciado pelas trocas dialógicas entre a universidade e a sociedade, na cidade e com a cidade, no território, com a população.

Estamos cientes de que há uma multidimensionalidade no problema no qual nos ocupamos em refletir. Ele não é simples! Discutir formação e o seu transbordar para a sociedade, nos convoca a dialogar com a própria sociedade, implodindo os muros que separam a produção do conhecimento acadêmico da realidade da vida cotidiana. 
Ensino, Saúde e Ambiente - V9 (3), pp. 269-282, Dez. 2016

\section{A FORMAÇÃO EM PSICOLOGIA}

Para refletir sobre a formação em Psicologia na atualidade, é imprescindível recorrer à história da formação em Psicologia no Brasil, articulando-o ao momento sócio-político no qual a Psicologia ganhou forças e formas. (PATTO, 2003 apud MARTINS, 2010, p.85).

Como pontuamos anteriormente, nosso trabalho pretende discutir a formação em Psicologia, através de ações extensionistas, a partir um tema que entendemos ser atual e relevante para a nossa sociedade: violência contra a mulher. Contudo, faz-se aqui necessário perpassar, mesmo que brevemente, a história da profissão de psicólogo que, necessariamente, se articula a questão da formação -, visto que precisamos compreender como problemáticas, que atravessam a sociedade hoje são compreendidas como também intrínsecas a formação e a prática do profissional psi.

Claro está que nosso objetivo aqui não é discutir a luta pela legalização da profissão, nem as condições de possibilidade para a sua regulamentação, que alguns autores localizam, especialmente, entre os anos de 1945-1962 (JUNIOR; CANTARINI; PRUDENTE, 2006), mas, salientar que, os últimos 50 anos - tempo relativamente pequeno quando falamos em história - foram de muitas mudanças, capazes de legitimar um novo lugar para o profissional psi e para a sua formação.

Apesar de alguns autores estimarem que a Psicologia venha sendo praticada no nosso país há mais de um século, que tenha havido inúmeras tentativas de instalação oficial da Psicologia no Brasil, foi há poucas décadas que ela foi reconhecida como profissão e se tornou possível a criação de cursos de formação. Afinal, foi somente a partir do dia 27 de agosto de 1962, com a promulgação da lei no 4.119 e, posteriormente, com o Decreto n. 53.464, de 21 de janeiro de 1964, que os psicólogos passaram a compor uma categoria profissional legalmente reconhecida. A partir daí, somente aqueles graduados em psicologia, em cursos reconhecidos, poderiam exercer a profissão.

Entendendo que nossa história nos dá condições de reconstruir nosso percurso, de evidenciar sucessos, enfrentamentos e erros, ela pode nos ser uma grande aliada nas investigações acerca da consolidação da identidade da Psicologia, especialmente quando se tratando de "de seus pressupostos, suas raízes e sua colocação no âmbito de contextos culturais e sociais determinados ao longo do tempo e do espaço" (MASSAMI, 1994, p.20). 


\section{Ensino, Saúde e Ambiente - V9 (3), pp. 269-282, Dez. 2016}

Na época de sua regulamentação como profissão, tanto a lei n. 4.119 quanto o Catálogo Brasileiro de Ocupações definiam a profissão de psicólogo limitando-a por seus "aspectos intervencionistas orientados para ajustamento e adaptação do individuo" (BOCK, 2001, p. 26). Seu trabalho era de “ajustamento, adaptação, auto-realização, desenvolvimento, convivência e desempenho, sempre supondo um estado de normalidade, adaptação, nunca definido" (BOCK, 2001, p. 26), podendo ser exercido em escolas, empresas ou clínicas.

A psicologia ainda não tinha a versatilidade e a abrangência que, atualmente, ela contempla. A inserção do psicólogo em novos espaços e contextos se deu a partir da interação da sociedade com o Estado por conquistas alcançadas; mas isto não se deu sem engajamento político de diversos psicólogos em diversos segmentos sociais. (Jornal do Conselho Regional de Psicologia - Rio de Janeiro, Ano 7, n.27).

O fato é que depois de duas décadas da regulamentação profissional, novas configurações sócio-políticas surgiram e demandaram dos psicólogos maior inserção/participação na sociedade. O processo de reabertura politica convocava a inserção de psicólogos na sociedade, para que estes pudessem participar de forma mais ativa e efetiva nas questões que atravessavam a sociedade como um todo (BOCK, 2001). E, para isto, seria necessário, não só a ampliação de seus espaços de intervenção, mas também a problematização da chamada "ciência psicológica" (BOCK, 2001).

Subsidiada pela inserção da categoria psi em diversos segmentos da sociedade, da ampla discussão sobre suas ações, a própria noção de fenômeno psicológico sofreu transformações (BOCK, 2001). Ou seja, integrou-se "a noção de fenômeno psicológico às noções de aspectos de cunho social, cultural e político" (p. 33). Tal mudança, ainda segundo Book (2001), pode ser percebida, inclusive, nas próprias produções bibliográficas da época, visto que o fenômeno psicológico cedeu lugar para questões acerca da profissão, seu papel na realidade e suas implicações na realidade cotidiana.

A autora evidencia que a nova posição da psicologia é visível na própria linha editorial da revista do Conselho Federal - Psicologia Ciência e Profissão -, que, no ano de 1984, anunciava o seguinte: “Os ventos da mudança social sopram entre nós, agitando não apenas a superfície dos acontecimentos... da realidade social que nos cerca” (Psicologia Ciência e Profissão, 1984, p.4 apud BOCK, 2001, p.30).

Na década de 90, a psicologia segue avançando e, com isso, a necessidade de se rever a formação. Os antigos currículos apresentavam-se bastante distantes desta nova e emergente Psicologia, plural e diversa, com novos atores, cujos temas centrais 
passaram a ser a democracia e a cidadania. Consequentemente, deu-se início a uma série de debates que, em 2004, culminaram na proposição das Diretrizes Curriculares Nacional para os Cursos de Graduação em Psicologia ${ }^{1}$.

Essas “orientações” marcam como meta principal uma formação voltada para a atuação, para a pesquisa e ensino em Psicologia, devendo ela assegurar princípios que evidenciam a sua amplitude. A partir destas 'orientações', os fenômenos psicológicos passaram a ganhar relevância em suas complexidades, interfaces e multideterminações, sendo compreendidos, de forma crítica, como fenômenos sociais, econômicos, culturais e políticos fundamentais, ao exercício da cidadania e da profissão (BRASIL, 2004/2011, Art.3).

Sabemos que a graduação é um momento de fundamental importância para a trajetória de formação do estudante de psicologia (YUKIMITSU, 1999 apud MARTINS, 2010, p. 85), visto que nela o aluno entrará em contato com referenciais relevantes para o exercício de uma determinada prática profissional. Contudo, sabemos que a graduação não pode se esgotar na sala de aula, visto que "a escola é o espaço onde só se ensinam as certezas construídas pela ciência, ignorando-se o fato de que a vida não é previsível e o imprevisto tende a ser negligenciado" (MAGALHAES, 2010, p.76).

É, neste sentido, seguindo a amplitude proposta pela DCN, das finalidades expressas na lei estabelece de Diretrizes e Base da Educação Nacional, que insistimos que o ensino superior também tem como finalidade: "estimular o conhecimento dos problemas do mundo presente, em particular os nacionais e regionais, prestar serviços especializados à comunidade e estabelecer com esta uma relação de reciprocidade", além de "promover a extensão, aberta a participação da população, visando à difusão das conquistas e benefícios resultantes da criação cultural e da pesquisa científica e tecnológica geradas na instituição" (BRASIL, 1996). No entanto, para isto, há de se ter consciência de o conhecimento se constrói em lugares variados.

A partir deste pequeno recorte, surgem alguns questionamentos: Como propiciar ao aluno em formação, no caso em Psicologia, uma aproximação da sociedade capaz de permiti-lo fazer uma leitura, a partir de seu contato com a realidade que o cerca? Como não apostar em uma formação que extrapola os limites universitários e coloca em cena aquilo que atravessa a nossa sociedade? Como dialogar com a

\footnotetext{
${ }^{1}$ Vale ressaltar que as Diretrizes Curriculares Nacionais para os Cursos de Psicologia, que data o ano de 2011, estabelecem normas para o projeto pedagógico complementar para a Formação de Professores de Psicologia. Estas não alteram o texto anterior, de 2004, excetuando os artigos que tratam especificamente da formação de professores (licenciatura).
} 
sociedade, indo além de uma aproximação esvaziada de sentidos e significados, capazes de propiciar mudanças significativas para ambos - universidade e a sociedade?

Estas questões são os eixos norteadores e condutores de nosso trabalho. Elas nos levam a refletir sobre a relevância da mais nova função da formação universitária a Extensão -, que é a que, por ser mais nova, carece de maiores investigações.

Como terceiro braço da formação, a Extensão universitária não ganha o devido (e merecido) destaque, sendo, por vezes, compreendida com tendo uma função menor, especialmente, em um tempo que os olhos atentos da universidade tendem se dirigir apenas para as pós-graduações, teoricamente locus privilegiado de produção de conhecimento e de investimento (ou vice-versa).

Dentre as três funções da universidade, ensino, pesquisa e extensão, a última é a mais nova e a que carece de maiores investigações. A maioria do trabalho realizado enfoca o processo de construção histórica da extensão e sua inserção dentro da sociedade com uma terceira função. Porém, poucos são aqueles que investigam a prática dos projetos, seu dia a dia, sua influência no processo de transformação de discentes e a sua contribuição para a consolidação de um campo de conhecimento. (CASTRO, 2004, p.2).

Contudo, não podemos perder de vista que é a Extensão que nos coloca 'de cara' com a pulsátil sociedade na qual estamos inseridos, que aposta no movimento, no formar com ação na sociedade, na cidade, com os cidadãos, abrindo espaços propiciadores de comutações e de metamorfoses.

\section{UNIVER-CIDADE}

O conhecimento não se estende do que se julga sabedor até aqueles que se julga não saberem; o conhecimento se constitui nas relações homem-mundo, relações de transformação, e se aperfeiçoa na problematização crítica destas relações. (FREIRE, 2006, p. 36).

Precisamos refletir sobre os instituídos presentes na universidade, para que, dessa forma, pudermos experimentar outras formas de a ocuparmos, pois, a formação, tal como a temos atualmente, não pode ser encarada como o único formato possível.

Isto não significa que tenhamos que, simplesmente, abandonar o que é o "tradicional", mas reconhecer que a formação precisa se dar em concomitância com a inserção da universidade na sociedade, e vice-versa. Mas, para isso, precisamos reconhecer a necessidade de ultrapassarmos os muros simbólicos que protegem à universidade. Permitir que o conhecimento - quer o dito acadêmico, quer aqueles que se 
instituem como saberes populares - verta de modo a propiciar algo novo: encontros dialógicos.

Sabemos que na tríade "pesquisa, ensino e Extensão", que compõe a universidade, seu último braço fica sempre um pouco apagado, como anteriormente dito. Isso cria universidades centradas em si mesmas, universidades que dialogam apenas com universidades, enclausurando o conhecimento na própria academia, sem gerar, de fato, algo que se acrescente para a população. Todavia, a Extensão universitária tem o poder de fazer diferente: promover o estar com as pessoas, no lugar onde elas de fato vivem, ou seja, na cidade.

A cidade, por sua vez, não é feita de prédios, avenidas, postos de saúde, hospitais, universidades, entre outras estruturas arquitetônicas. Também não é feita apenas de números que revelam quantos são seus habitantes e evidenciam seus índices. Para além destes, a cidade é feita de pessoas que contradizem as estatísticas, as probabilidades, as expectativas daqueles que gerenciam a vida na polis. A cidade é pulsátil e feita de pessoas concretas, singulares, com suas próprias histórias e percursos pela cidade, sempre em movimento.

Para fazermos a universidade estar na cidade e a cidade na universidade, precisamos apostar nas potencialidades emergem desta "mistura", com características emancipadoras também para os alunos em formação, capazes de transformar relações de sujeito-objetos em reciprocidades. (CASTRO, 2004, p.2). Precisamos retratar "a cidade em seu movimento cotidiano e vida, com suas ambiguidades e contradições" (DIOGO et al, 2011, p. 21).

Sabemos que críticas surgem quando falamos na mão dupla entre universidade e cidade. Muitas vezes, dizem que ela é incapaz de gerar um novo saber. Contudo, mesmo que não gere o saber, ela deve ser promotora de mudanças significativas, emancipadoras para que nem a universidade nem a cidade sejam sempre as mesmas. Universidade, em sua raiz etimológica, vem de universalidade. Mas, como propor o seu caráter universal dentro dos muros aprisionadores do saber acadêmico?

A educação tem caráter permanente. Não há seres educados ou não educados. Estamos todos nos educando. Existem graus de educação, mas esses não são absolutos. (FREIRE, 1983, p. 28).

A tradição cultural brasileira sempre privilegiou a universidade como o lugar de ensino, lugar de transmissão vertical do conhecimento. Mas, tal como a formação em 
psicologia, a partir dos anos 80, o conceito de Extensão universitária passou por transformações, ganhando novas significados e ressignificações.

O Fórum Nacional de Pró-Reitores de Extensão, em consenso sobre os fundamentos para elaboração das políticas de Extensão, decidiu, naquele tempo, que: "além de instrumentalizadora deste processo dialético de teoria e prática, a Extensão é um trabalho interdisciplinar que favorece a ampla e integrada do social". (Fórum Nacional, 1987 apud SERRANO, s/d, p.10).

Além disto, enfatizou o compromisso social da Universidade, na busca de solução dos problemas mais urgentes da população (NOGUEIRA, 2001), assim como a discussão sobre a indissociabilidade entre os fazeres na universidade. Paulatinamente, tornando-se destaque, estas foram dando corpo à ideia de que a extensão teria que, por missão, viabilizar a relação entre universidade e sociedade e vice versa. Contudo, isto ainda seria pouco.

A partir no final dos anos 90, se ressignificou a Extensão, através do Plano Nacional da Universidade Cidadã, cujos objetivos derivam da reafirmação da Extensão universitária pertencente ao processo acadêmico, definido e efetivado em função das exigências da realidade, indispensável à formação dos alunos, na qualificação do professor e no intercâmbio com a sociedade, além de assegurar a relação bidirecional entre universidade e a sociedade, de tal modo que os problemas urgentes recebam da Extensão atenção ação produtiva por parte da universidade, dando prioridade às práticas voltadas para o atendimento das necessidades sociais emergentes, dentre outros.

Mas, para que possamos dizer que a Extensão possa exercer sua potência transformadora, emancipatória e democrática, a Extensão deve ser, além de desenvolvida no diálogo e respeito aos sujeitos em suas culturas locais, capaz de ultrapassar sua vertente assistencial, que mais se apresenta como "politicas sociais compensatórias, suficientes para acalmar os conflitos sociais" (CASTRO, 2004, p. 4) do que a criação de novas possibilidades, saídas emancipatórias, que possam se inscrever em seus corpos e vidas.

Foi a partir da análise do que emerge de encontros dialógicos travados com e na sociedade, dos choques, dos mal-entendidos, que se tornou possível produzir, é que questões, que sejam realmente relevantes para a formação de um futuro profissional psi, capaz de produzir uma prática psicológica marcada e comprometida ética e politicamente. 
A vivência que advém da troca com a cidade nos permite nos posicionarmos a partir dela e não de fora dela, como fruto de abstrações.

\section{EMANCIPANDO SUJEITOS, ATRAVÉS DE AÇÕES NO TERRITÓRIO}

Como fora anteriormente evidenciado, os psicólogos foram convocados a participarem e se inserirem na sociedade, de forma mais ativa e efetiva, tocando em questões que fossem relevantes para ela. No nosso caso, o espinhoso tema, a violência contra a mulher, se destacou.

Diante dos números alarmantes que ocorrem na cidade, mesmo que sabidamente subnotificados, diante das fragilidades das politicas de saúde e de seus dispositivos, das políticas de proteção, a vida em nossa cidade convocava-nos a um diálogo horizontal com aqueles que nela vivem, visto que são muitas as mulheres que estão, cotidianamente, expostas a situações de violência.

O tema não é central na formação em Psicologia, embora possamos falar dos agravos de saúde, inclusive mental, efeitos das diversas violências sofridas em cada mulher que procura atendimento. Mas, longe estamos de pensar na violência que atravessa a vida das mulheres na cidade.

Entendendo que havia algo a ser feito, num emaranhado de possíveis outras prioridades, propusemos um projeto extensionista, cujo objetivo seria apenas escutar, para poder orientar mulheres sobre as violências vividas. Não objetivávamos nenhum efeito propriamente terapêutico, nenhum dado para pesquisa. Queríamos apenas trocar... E, com este objetivo, saímos visitando instituições pela cidade, colocando-nos a escutar suas histórias, criando rodas de conversas e, com isso, potencializando a comunicação universidade-cidade.

Entender como a violência atravessa, cotidianamente, nossos conterrâneos, como eles a veem, a vivenciam e a sentem, se colocou como desafio maior, pois, estudar a violência contra a mulher, numa perspectiva de gênero, através dos livros, tornava o patriarcado, a escravagismo e o cristianismo, que alicerça a estrutura da sociedade brasileira, instituições longínquas demais. Precisávamos nos colocar mais perto, bem perto e escutar aquelas que delas queriam apenas falar.

Apostando nisto, rodas de conversas, onde saberes circulam horizontalmente, foram criadas, possibilitando uma participação mais fluida e menos hierarquizada dos 
diferentes saberes presentes na cidade, promovendo olhares diferenciados e o surgimento de múltiplas histórias com recortes singulares.

Ao ganharem lugar, voz e vez, ao poder serem escutadas na sua dimensão de alteridade, as mulheres percebiam que eram, cotidianamente, violentadas por um único motivo: eram mulheres. A invisibilidade do problema, geralmente restrito ao âmbito das questões domésticas, passa a ganhar uma nova dimensão. As violências tornam-se públicas, concretas e visíveis, não só para os outros, mas também para elas que, imersas no sistema patriarcal, não conseguiam perceber como sendo absolutamente presentes.

Se para as mulheres algo se produziu, dizemos que também para aquelas em formação que promover saúde vai muito além de oferecer cuidados reparativos. É também se produzir bem-estar, é produzir sujeitos que possam exercer suas cidadanias, por se permitirem existir nas suas singularidades.

De fato, corroboramos Castro (2004), ao dizer que a Extensão produz conhecimento, a partir da experiência e traz para o aluno a capacidade de narrar sobre o seu fazer, produzindo um conhecimento narrativo. É um processo de ensinoaprendizagem baseado no ensinar a aprender, permitindo que os alunos caminhem com as próprias pernas.

A formação deve ser objeto de reflexão permanente e deve ir além das habilidades técnicas, que são necessárias, mas não suficientes, para o exercício de uma prática profissional. Precisa ser capaz de promover mudanças consistentes, em especial, quando estas tratam de temáticas tão arraigadas na sociedade como é a violência.

É exatamente porque não há separação entre conhecimento técnico e do compromisso político, que a Extensão pode ganhar um lugar fundamental na formação.

A formação universitária deve impulsionar o desenvolvimento de competências especificas para atuação profissional, enfatizando preceitos ético, técnicos e políticos. Campo no qual se inscrevem dimensões indissociáveis do ser humano para além de fenômenos biológicos e orgânicos, considerando sua inserção no contexto sócio histórico. O compromisso ético político relacionados à cidadania e a emancipação de sujeitos e coletividades. E é neste sentido que a extensão se torna fundamental possibilita experiências ampliadas, ricas em possiblidades para o aprendizado contrário aqueles anteriormente tidos como lugares de conhecimento. (BISCARDE, PEREIRA-SANTOS e SILVA, 2014, p. 178). 
Ensino, Saúde e Ambiente - V9 (3), pp. 269-282, Dez. 2016

\section{UMA APOSTA, APENAS!}

para a democratização da universidade, as dicotomias e assimetrias entre (...) ensino-pesquisa-extensão, (...) universidade e sociedade precisam ser superadas, ou no mínimo atenuadas (PAULA, 2010, p.220).

Nosso trabalho é um tanto quanto o de não desistir, resistir e sustentar às (trans) formações necessárias e fundamentais para o compromisso com a cidadania e com um bem comum. Estes seriam os princípios fundamentais que regem a profissão de psicólogo, mas também, a nosso ver, da Universidade, democrática e plural.

Pensando, repensando, retomando, construindo, devagar e com muito cuidado, que poderemos caminhar ainda mais na direção daquilo que queremos... Ou, como nos aponta Bock (2001): "é preciso perscrutar nossos instrumentos, por em xeque nossa visão de homem e mundo; assumir a dimensão política de nossa atuação profissional e analisar, criticamente, o alcance de nossas intervenções" (p.32).

O fato é que nossa caminhada jamais terminará, cabendo aos psicólogos participarem ativamente, e sempre, das reflexões de sua profissão, de sua prática e de ações junto à sociedade.

As atividades de Extensão surgem como, absolutamente relevantes, no âmbito da formação, uma vez que eles possibilitam não só o levantamento das necessidades e das demandas sociais, mas também sustentam princípios que norteiam não só uma sociedade mais democrática, diversa e plural, capaz de formar cidadãos. Eles evidenciam o papel fundamental da sociedade na construção de seu próprio projeto social.

Sair pela cidade escutando as mulheres acerca das violências experenciadas, em seu cotidiano, possibilita a construção de conhecimento acerca de uma temática pouco discutida na formação, apesar de absolutamente necessária, visto que elas se apresentam nas nossas mais diversas práticas profissionais. A violência não se circunscreve apenas no âmbito do privado, da clínica privada, quando outrora se pensava. Ela é pública, está na polis, atravessa sujeitos e corpos.

Vale ressaltar que, apesar de avançarmos na direção de pensarmos a Extensão no sentido de realizar algo que aponte para o seu caráter de indissociabilidade, apesar de toda sua reafirmação nas leis que regulamentam o ensino superior, verificamos com Castro (2004) que ela se apresenta mais comumente com "uma frase de efeito do que uma pratica que consiga efetivamente transformar os processos de ensino e de aprendizagem". (p.9). 
Mas, como tentamos evidenciar, apostamos em uma Extensão que, através de seus projetos, torna-se formas de aprendizagem e, como tal, "deve contribuir para implementação dos quatro pilares de educação contemporânea, ou seja, aprender a ser, a fazer, a viver junto e a conhecer”. (MORIM, 2000 apud CASTRO, 2004, p.10).

Se a universidade cabe preparar os cidadãos do futuro, numa perspectiva crítica, para enfrentar desafios cotidianos, ela é o espaço democrático e permanente de aprendizagem e (trans)formação. A Psicologia, por sua vez, como uma ciência e uma profissão, cuja formação deixou de ter um caráter puramente tecnicista e se dá nesta universidade democrática e plural, ela só pode ser pensada como comprometida ética e, politicamente, com a sociedade na qual está inserida.

\section{REFERÊNCIAS}

BISCARDE, D.G. dos S.; PEREIRA-SANTOS, M.; SILVA, L.B.. Formação em saúde, Extensão universitária e Sistema Único de Saúde (SUS): conexões necessárias entre conhecimento e intervenção centradas na realidade e repercussões no processo formativo. Interface (Botucatu), vol.18 (48), p. 177-86, 2014. Disponível em: http://www.scielo.br/scielo.php?script=sci arttext\&pid=S1414-

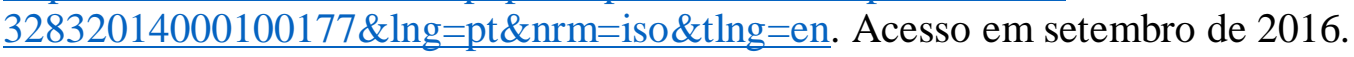

BOCK, A.M. B.. História da Organização dos Psicólogos e a concepção de fenômeno psicológico. In: JACÓ-VILELA, A.M.; CEREZZO, A.C.; RODRIGUES, H. de B. C.. (orgs). Clyo-Psyché Hoje. Rio de Janeiro: Relume Dumará, 2001.

BRASIL. Ministério da Educação. MEC. Lei de Diretrizes e Bases da Educação Nacional, 1. 9394, Brasília: MEC, 1996.

BRASIL. Lei n. 4.119, de 27/08/1962. Disponível em:

http://site.cfp.org.br/wp-content/uploads/2008/08/lei 1962 4119.pdf . Acesso em setembro de 2016.

BRASIL. Decreto n. 53.464, de 21 de janeiro de 1964. Disponível em: http://site.cfp.org.br/leis_e_normas/decreto-n-53-464-de-21-de-janeiro-de-1964/ Acesso em setembro 2016.

BRASIL. Resolução CNE/CES No 8, de 7 de maio de 2004. Diretrizes Curriculares Nacionais para os Cursos de graduação em Psicologia. Disponível em: http://portal.mec.gov.br/conselho-nacional-de-educacao/atos-normativos--sumulaspareceres-e-resolucoes?id=12991. Acesso em setembro de 2016.

BRASIL, Resolução CNE/CES nº 5, de 15 de março de 2011. Diretrizes Curriculares Nacionais para os Cursos de graduação em Psicologia. http://portal.mec.gov.br/conselho-nacional-de-educacao/atos-normativos--sumulaspareceres-e-resolucoes?id=12991. Acesso em setembro de 2016. 
CASTRO, L.M.C.. A universidade, a extensão universitária e a produção de conhecimentos emancipadores. Disponível em: http://27reuniao.anped.org.br/gt11/t1111.pdf. Acessado em outubro de 2016.

DIOGO, N.M.F.; CARVALHO, D.B.; ARAÚJO, J. S. de; MONTEIRO, F. S. A.C.T.; MACHADO, K. S.; NACIMENTO, M.C.B.; SILVA, N.S.; SILVA, N. F.; LOPES, P.O.. Nas vias do vento, a produção de vídeo como estratégia pedagógica na formação profissional de psicologia. Psicologia: Ensino e Formação. 2(1), p. 21-32, 2011.

FÓRUM NACIONAL DE PRÓ-REITORIA DE GRADUAÇÃO. O currículo como expressão do projeto pedagógico: um processo flexível. Textos da Oficina do FORGRAD, Niterói, 2000. Disponível em: http://abecin.org.br/data/documents/Curriculo_como_expressao_1.pdf . Acesso em novembro de 2016.

FREIRE, P. Pedagogia do Oprimido. 17 $7^{\mathrm{a}}$ ed. Rio de Janeiro: Paz e Terra, 1980.

Pedagogia da Autonomia: saberes necessários à pratica educativa. $34^{\mathrm{a}}$ edição. São Paulo: Paz e Terra, 2006

JORNAL DO CONSELHO REGIONAL DE PSICOLOGIA. Rio de janeiro. Ano 7, n.27. Disponível em: http://www.crprj.org.br/antigo/publicacoes/jornal/jornal27politicas-publicas.pdf . Acesso em outubro de 2016.

JUNIOR, A.S.; CANTARINI, M.; PRUDENTE, R.C.A.C..1945-1962: Os antecedentes da regulamentação da psicologia como profissão no Brasil. CES Revista, Juiz de Fora. v.18, n. 1, p. 157-176, 2006.

MAGALHAES, S.O.. Experiências de investigação da atitude transdisciplinar no contexto de formação de professores. Psicologia: Ensino e Formação. 1(1), p. 67-82, 2010. Disponível em: http://pepsic.bvsalud.org/pdf/pef/v1n1/07.pdf .Acesso em outubro de 2016.

MARTINS, A.M.. A formação em Psicologia e a percepção do meio rural: um debate necessário. Psicologia: Ensino e Formação. 1(1), p. 83-98, 2010. Disponível em : http://pepsic.bvsalud.org/pdf/pef/v1n1/08.pdf . Acesso em outubro de 2016.

MASSAMI, M.. Considerações Gerais sobre Psicologia e História. Temas em Psicologia, n. 3, p. 19-26, 1994. Disponível em: http://pepsic.bvsalud.org/pdf/tp/v2n3/v2n3a03.pdf. Acesso em outubro de 2016.

NOGUEIRA, M. D. P.. Extensão Universitária no Brasil: uma Revisão Conceitual. In. FARIA, D. S. de (org). Construção Conceitual da Extensão na América Latina. Brasília: Editora UNB. 2001.

PAULA. M. de F. C. Rumo à construção de uma universidade mais democrática e plural. Conhecimento e Diversidade, Institutos Superiores La Salle, Niterói, RJ n. 4, jul/dez, p. 11-24, 2010. 
Ensino, Saúde e Ambiente - V9 (3), pp. 269-282, Dez. 2016

SERRANO, R. M. S. M.. Conceitos de extensão universitária: um diálogo com Paulo Freire. Disponível em:

http://www.prac.ufpb.br/copac/extelar/atividades/discussao/artigos/conceitos de extens ao_universitaria.pdf 